\title{
How does Short-term Foreign Language Immersion Stimulate Language Learning?
}

\author{
Baron L. Savage \\ University of Colorado at Colorado Springs \\ Haning Z. Hughes \\ United States Air Force Academy
}

The dramatic events of September 11, 2001 shocked the nation and forced the United States government to acknowledge its tremendously inadequate capability in foreign language proficiency and global cultural awareness. In a memo to top Department of Defense (DoD) leadership addressing Operation Enduring Freedom (OEF) requirements, former Assistant Secretary of Defense Paul Wolfowitz indicated that DoD effectiveness in acquiring, maintaining, and employing language skills and area expertise had been severely limited. The primary reason for this limitation was the absence of a coherent strategy and integrated process within DoD for determining foreign language support requirements and managing DoD language assets. He asked the military services to support the Defense Foreign Language Proficiency Policy Committee in developing an overarching DoD strategy and policy to maximize return on investment in language education (Mueller, 2005).

Post 9/11 military operations reinforced the reality that the DoD needs a significantly improved capability in non-western European languages and dialects and a surge capacity to expand its language capabilities. As an initial step in the process, in 2005, the DoD produced the Defense Language Transformation Roadmap (DLTR) that directed the military services to coordinate their efforts toward more cohesive and universal goals and objectives (Wolfowitz, 2005). The document points out that $21^{\mathrm{st}}$-century conflicts will more likely be with combatants speaking non-European languages. Therefore, robust foreign language and foreign expertise in these areas is critical to sustaining coalitions, pursuing regional stability, and conducting multi-national missions in humanitarian, nation-building, stability operations, and security. This requires the military to be prepared to establish a larger, more effective, "global footprint" using language and cultural understanding to work effectively and cooperatively with coalition partners. Emphasis is now being placed on significantly increasing the number of officers speaking languages such as Arabic, Chinese, Farsi, Russian, Urdu, and other less commonly taught languages (Wolfowitz, 2005).

The impact of qualified language speakers on the battlefield was succinctly described by Major Kenneth Carey, an Army officer stationed in Iraq during Operation Iraqi Freedom,

If all our soldiers spoke Arabic we could have resolved Iraq in two years. My point is that language is obviously an obstacle to our success, much more so than culture. Even a fundamental understanding of the language would have had a significant impact on our ability to operate. (Snyder et al., 2008, p. 5) 
To address the glaring need articulated by Major Carey, the DLTR encouraged military forces to develop foreign language capabilities far beyond those generally available at the time.

The Department of Defense's efforts to increase member intercultural awareness and understanding are consistent with broader US trends in international education. Sandell, in her study regarding the impact of international education experience on undergraduate students, quoted U.N. Secretary-General Kofi Annan:

Perhaps more than ever, international understanding is essential to world peace. ... Globalization, migration, economic integration, communication, and travel are bringing different races, cultures, and ethnicities into ever closer contact with each other. ... Combining the familiar with the foreign can be a source of powerful knowledge and insight. (Sandell, 2007, p. 12)

However, university-level intermediate and advanced language programs often provide only about 30-40 actual classroom contact hours per semester. In an attempt to compensate for the lack of classroom contact hours in the service academy setting, the Air Force's new Culture, Region, and Language (CRL) Flight Plan provided for the creation of effective cultural immersion and crosscultural awareness training programs (Schwartz, 2009). At the U.S. Air Force Academy, summer language immersion programs now provide an average of 80 contact hours of intense language instruction over a four-week period, and 120 contact hours over a six-week program, two or three times the amount of instruction available in an average academic semester. Still, a fundamental question remains: How do student participants in short-term foreign language immersion programs actually benefit from the experience?

In recent years, colleges and universities have experienced a significant growth in short-term foreign language immersion programs, frequently at the expense of their more traditional semester and year-long study abroad programs. According to Chieffo and Griffiths (2009), economics has played a large role in expanding the use of short-term immersion programs. Students and parents are usually responsible for paying the tuition and overseas programs costs of study abroad programs, and the costs of short-term programs are generally much less expensive than the traditional longer-term programs. In addition, fewer government educational grants mean that more students are working to pay their way through school, and keeping a job is much easier when the student is gone for a few weeks rather than for a few months or a year. Furthermore, short-term summer immersion programs are very attractive to students who major in challenging subjects with little or no credit for language classes.

\section{Language Immersion Research}

Since the 1960s second language acquisition research has begun to address the influence of study abroad opportunities on the participants' linguistic abilities. Research into language acquisition resulting from study abroad immersion experiences has generally shown that overseas immersion opportunities positively affect second language development. 
One of the largest and most comprehensive studies to examine the effects of the study abroad experience was Brecht, Davidson, and Ginsburg's (1991) multi-year, multi-institutional research of Russian in a study abroad context. Interestingly, their study found that language aptitude, as measured by the Modern Language Aptitude Test (MLAT), was positively correlated to gains in reading proficiency but found no significant correlation with speaking or listening improvement (Brecht et al., 1991).

Freed (1998) pointed out that relying solely upon test scores to define language learning reveals very little about the actual linguistic progress made by study abroad participants. Therefore, when assessing the benefits that accrue to study abroad participants, researchers should consider variables beyond discrete tests scores in order to best predict language acquisition achievement. The efforts of such researchers as Brecht et al. (1995) and Lapkin et al. (1995) initiated the work that explores these issues.

These studies employed a wide variety of assessment instruments, including multi-skill tests, questionnaires, self-assessments and/or diary studies (Freed, 1995a). Freed also advocated the process of photo-journalism because it provides the participants with the opportunity to reflect upon their initial perceptions, either culturally or linguistically, and then to record an account of their actual experiences. Requiring study abroad participants to engage in these types of reflective exercises enables the student to gain a broader, more global perspective, and encourages the reduction of preconceived stereotypes that hinder personal growth and mutual cross-cultural understanding.

In addition to research studies predicting and measuring language proficiency growth, a number of comparative linguistic research projects attempted to evaluate the differences between language learning at home and abroad for different student groups. These studies were able to begin to differentiate specific linguistic features and language usage elements that may differ between the students who study only in conventional classrooms at home and those who experience a foreign language immersion program (Freed, 1998).

Zhang and $\mathrm{Yu}$ (2008) compared second language acquisition between study abroad participants and those whose only language learning came from a college classroom at their home university. They pointed out that some second language acquisition research has focused specifically on the role of study abroad in the language acquisition process, but most of that research has been directed at such languages as English, French, German, and Spanish. Little, if any, attention has been paid to the role of the study abroad program in the development of Chinese as a second language. With the dramatic increase in the number of students studying abroad in China, it is critical that research be conducted on how study abroad can contribute to Chinese language learning when compared to student experience in the home language learning environment (Zhang \& Yu, 2008).

Mendelson's (2004) study compared student expectations and achievements between a semesterlong study abroad program (14 weeks) and a summer study program (four weeks) at two separate locations in Spain. She noted a widely held belief that the significant advantage of the study abroad experience is that students have the opportunity to get outside of the formal classroom and interact with the people of any given culture. The results of her study revealed, however, that not all 
participants take full advantage of the opportunities provided, and not all participants, regardless of length of study, gain as much as they expected when surveyed prior to the study abroad experience.

Dwyer (2004) conducted a longitudinal study using 50 years of data acquired from a survey of 14,800 full-year, semester, and summer study abroad students participating in the Institute for International Education of Students foreign language immersion programs. She found that when compared to the semester study abroad participants, summer study students were much more likely to use their foreign language on a regular basis. She also found that summer study participants were more committed to subsequent language study than were their semester study counterparts; they were more passionate about studying another language and culture; and they were more likely to change majors, exhibiting a greater interest in academics as a result of their overseas experience. Dwyer concluded that the study's findings reinforce the benefits of short-term programs.

Kehl and Morris (2008) report that the number of U.S. students studying abroad continues to increase. According to Open Doors 2008 (Gardner \& Witherell, 2008), as recently as the 2006-2007 academic year, a record 241,791 students studied abroad, an increase of $8.0 \%$ over the previous year. This represents a growth in study abroad participation in the last decade of over $150 \%$. However, almost $50 \%$ of that growth must be attributed to the increase in popularity of short-term study abroad programs lasting fewer than eight weeks (Kehl \& Morris, 2008).

However, despite the fact that short-term programs represent more than half of all U.S. study abroad participation, Chieffo and Griffiths reported that "published work concentrating specifically on these programs is limited, often focusing on smaller, discipline-based groups of students and neglecting pre-program baseline data or a comparison group of peers on campus" (2009, p. 372). Furthermore, the literature that attempts to measure the success of the language acquisition process focuses primarily on extended immersion or study abroad programs lasting a semester to a full year or more (Poole and Davis, 2006). This study combined a quantitative assessment with a qualitative evaluation in an attempt to provide a meaningful judgment of how short-term language immersion programs stimulate the language acquisition process.

\section{Methodology}

This study employed a mixed methods approach consistent with methodological approaches employed by a number of prominent second language acquisition researchers (Brecht et al., 1991; Freed, Dewey, Segalowitz, \& Halter, 2004; Lewin, 2009; Pellegrino, 2005). The mixed methods research process model is shown in Figure 1. 
Baron L. Savage \& Haning Z. Hughes

Figure 1. Sequential Mixed Methods Research Design Model

\begin{tabular}{|c|c|c|}
\hline METHODS & PROCESS & OUTPUT \\
\hline $\begin{array}{l}\text { Quantitative Data } \\
\text { Collection }\end{array}$ & $\begin{array}{l}\text { *USAFA Registrar Office Historical Data; } \\
\text { Pre-test/Post-test Data; N=97 }\end{array}$ & $\begin{array}{l}\text { *Statistical Data } \\
\text { Pre-test/Post-test Data; N=97 }\end{array}$ \\
\hline $\begin{array}{l}\text { Quantitative Data } \\
\text { Analysis }\end{array}$ & $\begin{array}{l}\text { *Data Screening Conducted } \\
\text { *Repeated Measures Anova } \\
\text { *SPSS v.16 }\end{array}$ & $\begin{array}{l}\text { *Descriptive Statistics } \\
\text { *Repeated Measures Anova } \\
\text { Results }\end{array}$ \\
\hline $\begin{array}{c}\text { Phenomenologic } \\
\text { Study }\end{array}$ & $\begin{array}{l}\text { *Second/Third Year Chinese Students } \\
(\mathrm{N}=140) \\
\text { *Develop Interview/Survey/Photo-Journal } \\
\text { Questions }\end{array}$ & *140 Participants \\
\hline $\begin{array}{l}\text { Qualitative Data } \\
\text { Collection }\end{array}$ & $\begin{array}{l}\text { *Observations in/out of classroom } \\
\text { *In-depth Interviews, Survey Instrument } \\
\text { *Photo-Journal Compilation } \\
\text { *Follow -up Interview s/Questions } \\
\text { *Document Review }\end{array}$ & $\begin{array}{l}\text { *Survey responses } \\
\text { *Interview Notes } \\
\text { *Photo-Journal Projects } \\
\text { *Observation Notes }\end{array}$ \\
\hline $\begin{array}{c}\text { Qualitative Data } \\
\text { Analysis }\end{array}$ & $\begin{array}{l}\text { *Coding and Thematic Analysis } \\
\text { *Significant Statements Identified } \\
\text { *Language } \\
\text { *Culture } \\
\text { *Experience } \\
\text { *Benefits }\end{array}$ & $\begin{array}{l}\text { *Codes and Themes } \\
\text { *Analysis of Significant Statements } \\
\text { *Language } \\
\text { *Culture } \\
\text { *Experience } \\
\text { *Benefits }\end{array}$ \\
\hline $\begin{array}{l}\text { Integration of } \\
\text { Quantitative and } \\
\text { Qualitative Results }\end{array}$ & $\begin{array}{l}\text { *Interpretation and Analysis of Mixed } \\
\text { Methods Results }\end{array}$ & $\begin{array}{l}\text { *Discussion } \\
\text { *Implications and Recommendations } \\
\text { *Further Research }\end{array}$ \\
\hline
\end{tabular}

\section{Participants}

One hundred and forty US Air Force Academy (USAFA) cadets participated in the 2008-2010 Chinese summer language immersion programs conducted at Nanjing University in Nanjing, China, and during weekend excursions at prominent historical and cultural locations around the country. 
All 140 students were interviewed, completed a program questionnaire, created photo-journal projects, and took the pre- and post-test assessments in reading and listening. The summer language immersion program was conducted at Nanjing University's Institute for International Students. Students were housed in the Institute's student dormitory and attended 20 hours of intensive Chinese language classes each week with classes focusing on reading, speaking, listening, and writing. Nanjing University provided qualified native Chinese instructors who had been trained in teaching Chinese as a second language. All coursework instruction was conducted in the target language and students are expected to complete their homework each day before taking the opportunity to explore the local area and interact with native speakers.

\section{Quantitative Process}

Quantitative data in this study consisted of pre-test and post-test reading and listening scores for the students who participated in the Chinese language immersion program during the summers of 2008-2010.

\section{Assessment}

Nanjing University's Institute for International Students, which currently enrolls 1700 foreign students from over 70 countries around the world, administers USAFA's Chinese Summer Language Immersion program, targeting multiple levels of Chinese language proficiency. The Chinese language textbooks and source materials used by the Institute were designed by Beijing Language and Culture to prepare foreign students to pass the Chinese Proficiency Test, also known as the Hanyu Shuiping Kaoshi (HSK), the official Chinese national standardized test. The HSK was developed to assess the Chinese proficiency of non-native speakers, such as foreigners, overseas Chinese, and students of Chinese national minorities. The classroom reading and listening lessons at each level of Chinese proficiency are content-based, with topics ranging from Chinese culture, history, economy, and civilization, etc.

\section{Data Analysis}

Two repeated measures analysis of variance (ANOVA) between subjects factors were conducted to analyze the reading and listening scores. Repeated measures ANOVA was used to evaluate main effects of change in either reading or listening ability from pre-test to post-test. A between-subjects factor was also included to test effects between participant groups categorized as either first-time participants $(N=98)$ or repeat participants $(N=42)$ in the program as it has been demonstrated that lengthier immersion experiences may impact achievement in second-language learning (Brecht et al., 1995; Dwyer, 2004; Engle \& Engle, 2004). Of greatest interest to the researchers was the possibility of interaction effects. It was hypothesized that although all participants would increase in their reading and listening abilities, repeat participants were expected to outpace the performance of the first-time students. 


\section{Qualitative Process}

All 140 cadets participating in the 2008-2010 Chinese summer language immersion programs were interviewed, completed questionnaires, and compiled individual photo-journal projects that were used in the qualitative analyses. In addition, because triangulating data is an effective strategy in reducing bias, a common approach among second language acquisition researchers is to also use questionnaires in conjunction with interviews to gather student language information (DeKeyser, 2007; Freed \& Ferguson, 1995b; Freed et al., 2004; Huebner, 1998; Isabelli-Garcia, 2003; Lapkin et al., 1995).

Finally, each of the 140 cadet participants also completed a directed photo-journal project. Lewin suggested that students' initial perceptions are often colored by fundamental cultural biases, and that this type of experiential education enables participants to reflect and "think liberally about global problem and their solutions," encouraging within the participants a desire to become more effective global citizens (2009, p. xvii).

\section{Data Analysis}

All three data sources were examined for "significant statements, sentences, or quotes that provide an understanding of how the participants experienced the phenomenon" (Creswell, 2007, p. 61). Individual comments were reviewed to determine whether any trends or attitudes developed related to language and culture learning. The study was especially interested in any statements or themes related to the program's influence on language acquisition. Descriptions of moments when the student achieved a sudden clarity in the language acquisition process (the "Aha" moment) were looked for as were descriptions of how improvement in listening, speaking, reading, or writing occurred.

\section{Results}

\section{Quantitative Results}

Analyses of repeated measures ANOVA between subjects factors were run for each of the outcome variables: reading and listening.

The results for reading improvement showed a statistically significant main effect with a large effect size for all participants in improvement from pre-test to post-test $[F(1,95)=305.175, p<$ $.001, \eta^{2}=.743$ ] with participants showing notable improvement from pre-test mean of 31.68 ( $S E=$ $2.24)$ to a post-test mean of $63.62(S E=2.49)$. Like the reading results, a statistically significant main effect of improvement with a large effect size was found in listening skills from pre-test to posttest $\left[F(1,95)=498.393, p<.001, \eta^{2}=.840\right]$, as well as large statistical gains from a pre-test mean of $32.78(S E=1.94)$ to a post-test mean of $63.99(S E=2.37)$. In terms of interaction effects, no statistical differences were found between groups in their improvement from pre-test to post-test for either reading or listening. Contrary to the hypothesis that repeating students would outpace firsttime students in their improvement of reading and listening skills, first-time participants averaged greater gains over the repeating students even though these gains were not statistically significant. 


\section{Qualitative Results}

The questionnaire and interview questions asked were identical, although students were often more forthcoming and descriptive in their oral interviews. The surveys and interviews focused primarily on language learning success and the perceived benefits of the short-term foreign language immersion program, while the reflective photo-journals addressed cultural interactions with native speakers and descriptions of "Aha" moments. Although the questionnaire and interview questions also requested information about cultural interactions and "Aha" moments, the reflective photojournal portfolios were a particularly rich and descriptive source of information in these areas. By requiring study participants to complete specific tasks, conduct interviews with native speakers, and interact in the natural environment in different ways, the students were encouraged to push the limits of their listening and speaking abilities, and as they reflected on their efforts at the end of the day, they often found interesting insights that occasionally resulted in significant paradigm shifts, particularly with respect to cultural understanding and awareness.

Some interesting themes emerged in the qualitative data analyses and 370 significant statements (see Table 1) were identified.

Table 1. Significant Themes

\begin{tabular}{|c|c|c|c|c|}
\hline Categories & $\begin{array}{l}\text { Language } \\
\text { Acquisition }\end{array}$ & Culture & Experience & Benefits \\
\hline $\begin{array}{c}\text { Total } \\
\text { numbers: } \\
370\end{array}$ & $\begin{array}{l}\quad 205 \\
\text { Speaking } \\
\text { Listening } \\
\text { Reading } \\
\text { Writing }\end{array}$ & \begin{tabular}{l}
\multicolumn{1}{c}{51} \\
Interacting w/natives \\
Willingness to help \\
Dissidence \\
Cultural trip
\end{tabular} & $\begin{array}{l}\text { 54 } \\
\text { Pedagogical } \\
\text { Environmental }\end{array}$ & \begin{tabular}{l}
\multicolumn{1}{c}{60} \\
Immersion program \\
Individuals \\
Cultural awareness \\
Environment \\
Chinese Opinions
\end{tabular} \\
\hline
\end{tabular}

The qualitative data, as shown in Table 2 (below), was triangulated from three primary data sources: the personal interview, the survey, and the reflective photo-journal portfolio.

Language speaking. All program participants, whether first-time participants or repeat students, indicated that the short-term language immersion program provided them with myriad opportunities to improve their language skills. One first-time student stated, "Because I used it [the language] with native speakers, to attend language classes and cultural activities, and had the opportunity to hear the different colloquial accents, my language skills improved dramatically." A male first-time participant indicated, "I noticed a significant improvement in my speaking ability. Before the trip, I would think about each word and now I just say what I'm thinking without hesitation." 
Table 2 Table of Themes and Sources for Data Triangulation

\begin{tabular}{|c|c|c|c|}
\hline \multirow[b]{2}{*}{ Major Finding } & \multicolumn{3}{|c|}{ Source of Data } \\
\hline & Interview & Survey & Photo-journal \\
\hline \multicolumn{4}{|l|}{ Category 1: Language } \\
\hline *Speaking & $x$ & $x$ & $x$ \\
\hline *Listening & $x$ & $x$ & $x$ \\
\hline *Reading and Writing & $x$ & $x$ & \\
\hline \multicolumn{4}{|l|}{ Category 2: Culture } \\
\hline *Interacting with Native Speakers & $\mathrm{x}$ & $x$ & \\
\hline *Willingness to Help & $x$ & $x$ & \\
\hline${ }^{\star}$ Culture Trip Interactions & $x$ & $x$ & $x$ \\
\hline *Cultural Dissidence & $x$ & $x$ & $x$ \\
\hline \multicolumn{4}{|l|}{ Category 3: Experience } \\
\hline *Pedagogical & $\mathrm{x}$ & $x$ & \\
\hline *Environmental & $x$ & $x$ & \\
\hline \multicolumn{4}{|l|}{ Category 4: Benefits } \\
\hline *Immersion Program Value & $x$ & $x$ & $x$ \\
\hline *Understanding Individuals & $\mathrm{x}$ & $\mathrm{x}$ & \\
\hline *Enhanced Cultural Awareness & $x$ & $x$ & $X$ \\
\hline ^Total Immersion Environment & $x$ & $x$ & \\
\hline *Understanding Chinese Opinions & $x$ & $x$ & \\
\hline
\end{tabular}

Sixty percent of first-time participants (57 students) suggested that the immersion experience enhanced their confidence in speaking the language and improved their vocabulary and oral proficiency. A female first-time participant reported, "My spoken fluency has improved immensely, and I believe I could completely get by alone in China, if I had to." Another student stated, "I had no clue the extent of my speaking abilities until I came to China. I noticed how the more I talked, the more complex my sentences would become, and vocabulary became easier to remember." One first-time participant summed up the program's influence by noting, "A month in China is like a year in the States! I can already speak on a higher level than when I got here, and the extra practice has made me less timid about using the language as well."

However, not all first-time students made the same progress nor progressed at the same rate. Twenty-eight percent (27) of the students noted that they hesitated to engage native speakers and allowed other participants to speak for them until they gained the confidence necessary to engage in conversation. Therefore, student language acquisition success appeared to also be influenced by motivation, effort, and willingness to make mistakes. 
Repeat participants seemed to experience less hesitation in this regard than first-time participants, with a number of students reporting significant improvement in the spoken language from one year to the next. One repeat participant said:

Last year I tried speaking with the elderly man who played the 'erhu' but I could not understand him at all. This year, I was able to talk with him on two separate occasions for about 30 minutes with minimal problems. That is what stuck out to me the most!

Although the repeat participants did appear more willing to engage native speakers, the rate of successful language acquisition was directly proportional to the amount of effort expended in speaking the language. Instructors observed that even some repeat participants appeared to spend significant amounts of time in large groups, where they tended to speak English frequently and allowed more assertive students to interact with native speakers on their behalf. Again, individual student language proficiency growth appeared to be a function of motivation, effort, and willingness to engage with native speakers, despite the risk of not always understanding the entire conversation.

Language listening. Listening comprehension was another area of noted improvement by most participants. Eighty-seven percent (122) of the students suggested that their understanding of spoken Chinese had improved and that a positive result was that they could express their thoughts in Chinese better. A first-time participant, echoing classmate comments, stated, "My listening comprehension improved dramatically, and as a result, my ability to create useful phrases and sentences also improved." Another first-time participant said, "My listening skills dramatically increased by constantly and actively listening to native speakers." This process of "active listening" substantially contributed to student language learning. By taking advantage of the opportunity to be surrounded by native speakers and immersed in the language, students were able to hear common words and phrases repeatedly, and this repetition was reported to assist in rapid language acquisition.

Returning participants also recognized an improvement in their listening comprehension. One returnee noted, "I believe my tangible listening skills improved dramatically. I could understand 60$65 \%$ of what was being said or asked of me." A female student commented, "I find myself understanding more this year, especially when I observe their body language."

Language reading and writing. First-time and returning participants also commented on their reading and writing skills. Ninety percent (126) of the study participants noted that the biggest obstacle in learning to read and write Chinese was the lack of time to practice writing and the fact that the characters to be memorized could only be found in the textbooks. Short-term language immersion participants commented on the value of being surrounded by Chinese characters on signs, billboards, posters, and especially on restaurant menus, as they endeavored to remember them. A female student stated, "I believe I am a lot better at writing and remembering characters, especially the ones you use often, which was a goal of mine."

Returning students also noted that the character memorization process was difficult because it seemed to require repeated effort to memorize and retain each symbol. However, participants reported that the process was facilitated by the immersion environment that provided numerous 
opportunities and contexts within which to view the characters. One returning student said, "Being surrounded by Chinese characters really made a difference. I learned more characters and improved my Mandarin 'pinyin' this year." Another said, "My characters increased because I saw them everywhere I looked, and I also learned some new vocabulary. Also, I learned some Confucius sayings which are very interesting, and my reading definitely improved."

Immersion program value. To gain a better understanding of how the study participants felt about the benefits of the short-term immersion program, the question was asked, "How do you feel spending time in China on this immersion program has helped your language learning? Participants responded by stating: "In reading and speaking. Every day we read from textbooks written only in Chinese, and we saw characters everywhere we went. We were able to interact with natives all the time and receive immediate feedback."

First-time students found substantial language learning benefit from the immersion environment. The short-term immersion environment positively influenced first-time student outcomes by, as one reported, "forcing me to listen to Chinese every day as opposed to 2-3 hours per week." One significant comment, echoed by 22 of the participants, was that "The program provided intense Chinese language training, which reinforced the foundation I've been building the last three years." Students also emphatically insisted, "Nothing makes you learn faster than being surrounded by the language. Total immersion is the only way to really get good." A related benefit to the shortterm immersion, according to a number of respondents, was that the immersion environment provided relevance and context to the language learning process. One first-time participant summed up this thought by stating, "I have been plunged into China's language and culture, which has given me more opportunities to practice my Chinese skills while creating relevance."

Returning participants again noted similar feelings. One participant expressed the benefit of the immersion program by saying, "Everywhere I go I use Chinese, hear Chinese, and see Chinese. In the States, I have to open my textbook or go to it. In China, it comes to me."

The rich dimensions and the benefits described by study participants are difficult to measure quantitatively. However, it is clear that the study abroad participants felt both a sense of pride in their accomplishments and a recognition that their language proficiency had improved as a result of their short-term language immersion experience. It is also apparent that the immersion environment provided increased motivation for program participants to pursue the language acquisition process.

\section{Critical Periods of Language Acquisition}

In an effort to identify specific moments of language acquisition success, the study asked participants to specifically highlight those critical periods in their language learning in which they recognized a significant growth or development. These critical periods have been termed "Aha" moments.

Pedagogical "Aha" moments. These moments occurred in the classroom and the timing was different for each participant. Forty-three percent (60) of the students noticed an improvement during the first week of class, 31\% (43) during the second week of class, $11 \%$ (15) during the third 
week of class, while the remainder reported no single moment of sudden clarity, but rather a general improvement over the course of the immersion program. While the study abroad classroom played an important role in the language proficiency gain experienced by a majority of participants, one student summed up the importance of individual responsibility for active learning by stating,

At first, I treated class in Nanjing much as I did at home. I was quiet most of the time and asked only a few questions. But when I realized that it benefited me and the entire class if I was more active, I was constantly trying to practice and volunteer in class and found that I knew more than I expected.

Rather than a sudden moment of clarity, 15\% (21) of the students reported that over the course of the program they realized that they were no longer speaking slowly and haltingly. Five participants noted the influence of short-term immersion program language instructors in assisting them achieve their "Aha" moments. A female student reported: "My interaction with my speaking teacher, who actually made me want to learn and who spoke slowly and understandably, helped immensely." Returning participants also experienced "Aha” moments. One returning cadet mentioned:

One day while the teacher was talking, I realized that I was understanding everything she was saying. She said, 'It isn't until after your foundation is solid that you can build a house.' I realized that up to that point I didn't have a solid enough grasp of the basics in grammar and vocabulary.

With respect to these pedagogical "Aha" moments, participants appeared to recognize that although the language immersion program provided opportunities for significant language proficiency growth, it was still the responsibility of the student to take advantage of the program. One student reported, "I realized in class that if I actually did homework and read ahead before class, going over that same material with the teacher does wonders. What a concept!"

Environmental "Aha" moments. Although about 25\% (35) of the short-term language immersion program participants reported pedagogical influences in their "Aha" moments, more than $55 \%$ (77) of the participants described their moments of sudden clarity as they occurred while interacting with native speakers in the natural environment outside of the formal classroom. Again, although they all described moments of clarity that occurred at various times over the course of the short-term language immersion program, the common denominator was that these moments of environmental language clarity occurred as the students became more comfortable using the language and interacting with the people, with first-time participants expressing far more initial discomfort than returning students. One first-time participant, expressing a sentiment shared by many of her classmates, said,

After about one week in China. I started understanding more Chinese and was able to more naturally construct sentences and convey my thoughts more clearly. I think from simply being surrounded by the culture I naturally responded with clearer understanding.

A number of first-time students described their moments of sudden language clarity and the 
excitement they felt at the moment. One cadet described his "Aha" moment as occurring "when I had the ability to have decent sustainable conversations in Chinese and was able to communicate abstract ideas." Another stated that "My 'Aha' moment was when I was sitting in a cab holding a very leisurely conversation with the cab driver, and I felt I really connected."

Returning immersion participants noted similar "Aha" moments outside of the classroom. One student described his experience at a shop in Xian: "A vendor asked me a pretty lengthy question about how I felt about China's economic development, and I remember being surprised when I understood all of what she said!"

Forty-three percent (18) of the returning students reported that their "Aha" moments came while negotiating to buy items in small shops or markets. A returning student stated:

Last year, I tried speaking with a sales clerk in Beijing and she needed to use a lot of English with me. This year it was all in Chinese and we talked longer. It made me realize I had really progressed. Being surrounded by the language helped me reach that point.

Regardless of the timing or the circumstances surrounding the specific "Aha" moment, shortterm language immersion participants recognized that the language immersion experience significantly contributed to their language proficiency gain. As one student suggested, "Being surrounded by the language helped me reach that point."

\section{Discussion}

This study revealed that language immersion participants experienced a statistically significant improvement in both listening and reading scores from pre-test to post-test. However, there was no statistically significant difference between students with previous language immersion participation and first-time participants in listening and reading scores from pre-test to post-test.

These results are of interest given that the repeat participants had all had at least two additional semesters of formal university classroom instruction and one previous four-week in-country language immersion experience over their first-time colleagues. One possible explanation for these test results is that while the immersion program does an excellent job of giving the students a significant boost in their language learning proficiency from pre- to post-test, once the students return home, they are unable to maintain their initial language proficiency gain. Students at USAFA are unable to major in a foreign language and must therefore concentrate on more important coursework related to their majors once they return from overseas. In addition, they must also fulfill significant military and physical fitness requirements that occupy additional time that might otherwise be spent on academics. Moreover, second and third year students average only 30 language contact hours in an entire semester compared with 80 contact hours in a four-week immersion program and 120 contact hours in a six-week program. Furthermore, in the overseas immersion environment, students average an additional 8 contact hours per day (240 hours/four weeks; 360 hours/six weeks) outside the classroom interacting with native speakers. It is not surprising that their language proficiency gain during the immersion program is so impressive, nor is it surprising that they are unable to maintain that gain, given their limited language learning contact hours after they return. Further research is 
suggested to determine what steps the Chinese program can take to help students maintain their language proficiency gain in the current academic environment.

Jackson (2008) noted that researchers still have a great deal to learn about how study abroad participants actually spend their time while overseas, which language they speak when interacting with friends and associates, and the amount of time and focus they spend in actual language study.

The primary impediment to language learning observed in this study was, in fact, the manner in which participants chose to use their time. The students who achieved the greatest assessment gains were also the same students who completed all of their assigned homework and then made the effort to get out of their dorm rooms and explore the city. They were also the same students who made every effort to interact with native speakers in the natural environment and who came to their classroom instructors or escorts nearly every day with a list of new words or phrases that they had heard and were trying to incorporate into their foreign language speech. Oxford and Shearin (1994) pointed out that motivation is considered one of the primary factors in successful second language acquisition. They insisted that "motivation determines the extent of active, personal involvement in L2 learning. Conversely, unmotivated students are insufficiently involved and therefore unable to develop their potential L2 skills" (p. 12). In addition, Pellegrino (1998, 2005) suggested that learner attempts to interact with native speakers involves a great deal of social personal risk. Students in this study who successfully negotiated the communicative process with native speakers overcame their initial fear and made the effort to communicate despite the myriad of language mistakes.

With respect to the amount of research previously conducted to identify measurable outcomes from a short-term study abroad immersion experience, Woodman (2001) noted:

Little research has identified specific areas of change, and/or specific timeframes, in which such change may occur. These gaps in the research literature have effectively limited the ability of theories of second language acquisition and second language pedagogy to identify critical periods in language acquisition and/or critical factors in language teaching, especially with respect to their impact in short-term programs. (p. 2)

This research study asked first-time and returning short-term language immersion participants to identify specific moments in the classroom and while interacting with native speakers, during which they recognized that their language proficiency had improved in a noticeable manner.

Although the timeframes varied, most study participants were able to articulate an "Aha" moment regardless of whether that moment occurred in the language immersion classroom or the natural environment. For some participants, the "Aha" moment was a gradual awareness that they could both comprehend the foreign language input and produce comprehensible foreign language output. For others, it was a sudden moment when everything came together and the language suddenly made sense. These findings suggest that Woodman's (2001) critical periods in the language acquisition process do exist and can be identified in short-term language immersion program. Further research is suggested to determine what interventions, if any, may be employed to accelerate 
the process so that short-term language immersion program participants can achieve maximum measurable results from their language learning efforts.

Over the last ten years, a number of second language acquisition researchers conducted comparative studies analyzing the differences in participant language proficiency gains between traditional long-term immersion programs and the more recent, and increasingly common, shortterm programs (Chieffo and Griffiths, (2009), Dwyer (2004), Medina-Lopez-Portillo (2004), and Mendelson (2004)). The USAFA short-term language immersion study found that short-term study abroad students are extremely interested and committed to using the target language, and that $87 \%$ of short-term study abroad participants take additional Chinese classes once they return home, despite the fact that they may have completed their university-mandated language requirements. Although available short-term study abroad research is limited, the material that has been published provides "compelling evidence that students are changed by even a month-long study abroad experience in ways that contribute meaningfully to campus cross-cultural competence development efforts" (Chieffo \& Griffiths, 2009, p. 373).

\section{Conclusion}

According to the House Armed Services Committee report (Snyder et al., 2008), the military's lack of second language skills and cultural expertise is not an isolated phenomenon but is symptomatic of a greater public issue facing the country. The fact is that not only does the military need more language proficient and culturally aware individuals to perform its humanitarian, safety, and security missions, but in order to remain competitive in the global marketplace, the United States as a whole also needs its citizens to recognize the importance of developing these language and cultural skills.

In recent years, colleges and universities have experienced a significant growth in short-term foreign language immersion programs. Although short-term language immersion programs have been shown to stimulate language learning, much remains to be learned about how to assist participants with maintaining their newly acquired foreign language proficiency. In a study of thousands of students in over 100 European institutions of higher learning, Coleman (1998) found that language proficiency gain was dramatically reduced after students returned home from a year abroad language immersion program. The results of this study suggest that for short-term language immersion programs, the rate of loss may be even higher than for long-term programs. The challenge, then, will be to design formal classroom programs that can maintain and build upon the foreign language proficiency gains achieved in the short-term program.

As the results suggest, USAFA's short-term language immersion program, despite its brevity, should remain an important component of the Air Force's effort to significantly increase the number of language-enabled Air Force members (Schwartz, 2009). The process of significantly increasing the foreign language proficiency of large numbers of military members poses a significant challenge. There are currently over 33,000 Air Force members engaged in military, humanitarian, and safety and security operations worldwide. In order to maximize their influence, these Air Force members need to acquire sufficient foreign language proficiency in order to operate efficiently in culturally and 
linguistically complex environments. Proficient second language skills will enable them to more effectively encourage reform, promote understanding, and convey respect for other peoples and cultures, which should result in increased cooperation, peaceful interaction, and mutual understanding (Mueller, 2008).

The fact that the short-term foreign language immersion program has been shown to stimulate language and cultural learning is good news for the Department of Defense, the United States Air Force Academy, and for colleges and universities around the country. Short-term programs interfere less with extensive military education and training processes and with college and university academic program demands, yet they still provide significant exposure to the target language and culture for the participants. They also cost less, allowing scarce resources to be allocated efficiently to military units and to university colleges and departments. In addition, should the results of this study prove generalizable to other colleges and university short-term immersion programs, language program stakeholders will be better prepared to justify and validate the individual and organizational funds expended to support program participation.

\section{References}

Brecht, R. D., \& Robinson, J. L. (1995). On the value of formal instruction in study abroad: Student reactions in context. In B. F. Freed (Ed.), Second language acquisition in a study abroad context (pp. 317-334). Philadelphia: John Benjamins North America.

Brecht, R. D., Davidson, D. E., \& Ginsburg, R. B. (1991). On evaluating language proficiency gain in study abroad programs: An empirical study of American students of Russian. Paper presented at the International Congress of MAPRIAL, Moscow, Russia.

Brecht, R. D., Davidson, D. E., \& Ginsberg, R. B. (1995). Predictors of foreign language gain during study abroad. In B. F. Freed (Ed.), Second language acquisition in a study abroad context (pp. 37-66). Philadelphia: John Benjamins North America.

Chieffo, L., \& Griffiths, L. (2009). Here to stay: Increasing acceptance of short-term study abroad programs. In R. Lewin (Ed.), The handbook of practice and research in study abroad (pp. 365380). New York: Routledge.

Coleman, J. (1998). Language learning and study abroad: The European perspective. Frontiers: The International Journal of Study Abroad, 4(1), 167-203.

Creswell, J. W. (2007). Qualitative inquiry \& research design: Choosing from among five approaches (2nd ed.). Thousand Oaks, CA: Sage Publications.

DeKeyser, R. (2007). Practice in a second language: Perspectives from applied linguistics and cognitive psychology. Cambridge, England: Cambridge University Press.

Dwyer, M. M. (2004). More is better: The impact of study abroad program duration. Frontiers: The Interdisciplinary Journal of Study Abroad, 10(1), 151-164.

Engle, L., \& Engle, J. (2004). Assessing language acquisition and intercultural sensitivity development in relation to study abroad program design. Frontiers: The Interdisciplinary Journal of Study Abroad, 10(1), 219-236.

Freed, B. F. (Ed.). (1995a). Second language acquisition in a study abroad context. Philadelphia: John Benjamins North America. 
Freed, B. F. (1998). An overview of issues and research in language learning in a study abroad setting. Frontiers: The Interdisciplinary Journal of Study Abroad, 4(2), 31-60.

Freed, B. F., \& Ferguson, C. A. (1995b). What makes us think that students who study abroad become fluent? In B. F. Freed (Ed.), Second language acquisition in a study abroad context (pp. 123-148). Amsterdam, Netherlands: John Benjamins.

Freed, B. F., Dewey, D. P., Segalowitz, N., \& Halter, R. (2004). The language contact profile. Studies in Second Language Acquisition, 26(2), 349-356.

Gardner, D., \& Witherell, S. (2008). U.S. study abroad up 8\%, continuing decade-long growth. Institute of International Education, 1(10). Retrieved from http://opendoors.iienetwork.org/?p=131592

Huebner, T. (1998). Methodological considerations in data collection for language learning in a study abroad context. Frontiers: The Interdisciplinary Journal of Study Abroad, 4(1), 1-30.

Isabelli-Garcia, C. L. (2003). Development of oral communication skills abroad. Frontiers: The Interdisciplinary Journal of Study Abroad, 9(1), 149-173.

Jackson, J. (2008). Language, identity and study abroad. Oakville, CA: Equinox Publishing.

Kehl, K., \& Morris, J. (2008). The differences in global-mindedness between short-term and semester-long study abroad participants at selected private universities. Frontiers: The Interdisciplinary Journal of Study Abroad, 15(1), 67-79.

Lapkin, S., Hart, D., \& Swain, M. (1995). A Canadian interprovincial exchange: Evaluating the linguistic impact of a three-month stay in Quebec. In B. F. Freed (Ed.), Second language acquisition in a study abroad context (pp. 67-94). Philadelphia: John Benjamins North America.

Lewin, R. (Ed.). (2009). The handbook of practice and research in study abroad. New York: Routledge.

Medina-Lopez-Portillo, A. (2004). Intercultural learning assessment: The link between program duration and the development of intercultural sensitivity. Frontiers: The Interdisciplinary Journal of Study Abroad, 10(1), 179-199.

Mendelson, V. G. (2004). Hindsite is 20/20: Student perceptions of language learning and the study abroad experience. Frontiers: The Interdisciplinary Journal of Study Abroad, 10(1), 43-63.

Mueller, G. A. (2005). Language maintenance study. Colorado Springs, CO: United States Air Force Academy.

Mueller, G. A. (2008). Air Force culture, region, and language strategy. Washington DC: United States Government Printing Office.

Oxford, R. L., \& Shearin, J. (1994). Language learning motivation: Expanding the theoretical framework. Modern Language Journal, 78(1), 12-28.

Pellegrino, V. A. (1998). Student perspectives on language learning in a study abroad context. Frontiers: The Interdisciplinary Journal of Study Abroad, 4(1), 91-120.

Pellegrino, V. A. (2005). Study abroad and second language use: Constructing the self. New York: Cambridge University Press.

Poole, D., \& Davis, T. (2006). Concept mapping to measure outcomes in study abroad programs. Social Work Education, 25(1), 61-77.

Sandell, E. J. (2007). Impact of international education experiences on undergraduate students. Delta Kappa Gamma Bulletin, 73(4), 12-39. 
Schwartz, N. A. (2009). Air Force culture, region, and language flight plan. Washington, DC: United States Air Force.

Snyder, V., Akin, W. T., Spratt, J., Bartlett, R. G., Sanchez, L., Jones, W. B., et al. (2008). Building language skills and cultural competencies in the military: DoD's challenge in today's educational environment. Washington DC: U. S. House of Representatives Committee on Armed Services.

Wolfowitz, P. (2005). Defense language transformation roadmap. Washington DC: Office of the Secretary of Defense.

Woodman, K. (2001). A study of linguistic, perceptual, and pedagogical change in a short term intensive language program. (Unpublished Dissertation). University of Victoria. Victoria, British Columbia.

Zhang, D., \& Yu, Y. (2008). Context of learning and requesting in Chinese as a second language: An exploratory study of students learning Chinese in study abroad and at home contexts. Journal of the Chinese Language Teachers Association, 43(1), 73-92. 